\title{
O SABER/CONHECIMENTO: CAMPOS EPISTÊMICOS
}

\author{
EL SABER / CONOCIMIENTO: CAMPOS EPISTÉMICOS
}

THE KNOWLEDGE: EPISTEMIC FIELDS

\author{
Maria Aparecida VIEIRA DE MELO ${ }^{1}$ \\ Erenildo JOÃO CARLOS ${ }^{2}$
}

\begin{abstract}
RESUMO: Tratar da natureza do conhecimento é entender que historicamente vem sendo produzidas reflexões acerca da sua complexidade. A historicidade do conhecimento é desdobrada em teorias epistemológicas que ampliam as possibilidades de se operar com determinado tipo de conhecimento, conforme seu objeto de estudo, e, consequentemente, o método científico legitima determinado conhecimento. Assim, a reflexão que se pretende realizar faz jus às bases epistêmicas do conhecimento, desde o método positivista/empirista ao pensamento complexo, ou seja, historicamente o conhecimento se amplia por meio de seus métodos e domínios, a depender da subjetividade do sujeito em relação ao seu objeto, tratando-o objetivamente. Neste sentido, a tese que subsidia esta reflexão é a disciplinaridade do conhecimento.
\end{abstract}

PALAVRAS-CHAVES: Saber. Conhecimento. Epistemologia. Complexidade.

RESUMEN: Tratar de la naturaleza del conocimiento es entender que históricamente vienen siendo producidas reflexiones acerca de su complejidad. La historicidad del conocimiento se desdobla en teorías epistemológicas que amplían las posibilidades de operar con determinado tipo de conocimiento, según su objeto de estudio, y, consecuentemente, el método científico legitima determinado conocimiento. Así, la reflexión que se pretende realizar hace jus a las bases epistémicas del conocimiento, desde el método positivista / empirista al pensamiento complejo, o sea, históricamente el conocimiento se amplía por medio de sus métodos y dominios, a depender de la subjetividad del sujeto en relación a su objeto, tratándolo objetivamente. En este sentido, la tesis que subsidia esta reflexión es la disciplina del conocimiento.

PALABRAS CLAVES: Saber. Conocimiento. Epistemología. Complejidad.

ABSTRACT: To deal with the nature of knowledge is to understand that historically there have been reflections about it is complexity. The historicity of knowledge is unfolded in epistemological theories that expand the possibilities of operating with a

1 Universidade Federal de Pernambuco (UFPE), Recife - PE - Brasil. Docente. Doutoranda pela Universidade Federal da Paraíba (UFPB) - PPG em Educação. ORCID: <https://orcid.org/0000-00016288-9405 >. E-mail: m_aparecida_v_melo@hotmail.com

${ }^{2}$ Universidade Federal da Paraíba (UFPB), João Pessoa - PB - Brasil. Docente do Departamento de Fundamentação da Educação Programa de Pós-Graduação em Educação. E-mail: erenildojc@hotmail.com 
certain type of knowledge, according to its object of study, and consequently, the scientific method legitimates certain knowledge. Thus, the reflection that is intended to do justice to the epistemic bases of knowledge, from the positivist/empiricist method to complex thinking, that is, historically, knowledge is expanded through its methods and domains, depending on the subjectivity of the subject in relation to its object, treating it objectively. In this sense, the thesis that supports this reflection is the disciplinarity of knowledge.

KEYWORDS: Knowledge. Epistemology. Complexity.

\section{Introdução}

Tratar da disciplinaridade do conhecimento é evidenciar que ao longo do tempo histórico os estudos voltados para esta categoria operam no reconhecimento de que o conhecimento é um modo de saber elaborado, ou seja, cientificamente produzido. Assim, a produção do conhecimento é disciplinar, isto é, limitada numa visão linear e cartesiana que tem se perdurado ao longo do tempo no modo de operar o conhecimento.

Sabe-se que existem vários tipos de saberes, que sistematizados no campo da investigação científica corroboram para a produção do conhecimento. Isso porque o conhecimento não é um dado ou revelação, ele é produzido no campo de sua existência, isto é, a depender do contexto (social, econômico, político, histórico e cultural), da circunstância, da realidade, da linguagem e do campo em que está inserido, é escavado por meio do uso do domínio metódico para sua produção. Ou seja, acontece não só a seleção do conhecimento em meio aos saberes, mas a forma de como é selecionado o conhecimento lhe configura o novo conhecimento.

Foi possível compreender numa perspectiva complexa que o conhecimento está mergulhado, ficando assim, evidente, que o saber é diferente do conhecimento. Por este último ser refinado, expresso e condensado num domínio específico de sua natureza epistêmica, conferindo-lhe a disciplinaridade que opera a produção do conhecimento a partir da diversidade de saberes que o envolve.

É neste intuito de refinamento do conhecimento que o método ganha destaque, pois o conhecimento é uma forma de saber, ou seja, um saber elaborado. Em outras palavras: a elaboração do saber por meio do método confere a ele o status de conhecimento. Ser elaborado é uma característica do conhecimento.

Considerando, portanto, que o saber está em um campo/território maior, assim se opera o conhecimento, pois este não é uma crença, não é um valor, não é um mito, não é 
uma tradição, não é um dogma. Esses são saberes que sistematizados pela razão metódica operam rupturas nos próprios saberes já existentes em prol da produção de conhecimento novo, sendo este um saber elaborado, ou seja, a produção do conhecimento cientificamente à luz de um domínio/método.

Entende-se que o conhecimento operado metodologicamente encontra-se nas áreas de filosofia, teologia, sociologia, história, psicologia, geografia, antropologia (BURKE, 2012), áreas disciplinares que, após o refinamento pelo trabalho operado metodologicamente, emerge o novo conhecimento. Explico-me: um "fato" é apenas um fato que acontece no contexto social, mas quando esse fato é tratado pela ciência da história torna-se um conhecimento.

Deste modo, existem multirreferências do conhecimento que transcendem determinadas áreas científicas, para além de campos específicos que concernem com o conhecimento produzido, daí o conhecimento não é só disciplinar, é interdisciplinar, é transdisciplinar, é multidisciplinar, pois se constitui por ramificações que estão alocadas em dimensões múltiplas de suas áreas, fazendo jus à sua complexidade (SANTOS, 2017; MORIN, 1999; BURKE, 2012, PONTY, 2006). Entretanto, a forma como se opera com a produção do conhecimento é disciplinar.

Nesta perspectiva de entendimento acerca do primado do conhecimento, parte-se da premissa de que este é retroalimentando pela visão epistêmica que ao longo da história foi se ampliando à luz de teóricos clássicos que têm ressignificado a compreensão do conhecimento, os fenômenos que operam a sua produção.

Assentam-se, assim, curiosidades epistemológicas no campo do saber que transcendem para além do conhecimento novo que emerge a partir daquele já existente, pois perceber que o processo de autonomia se estabelece na feitura do conhecimento é crucialmente necessário neste processo, à luz de visões singulares historicamente construídas e ao mesmo tempo holísticas, permeando o novo que a depender da essência do saber se constitui no ato de operar rupturas, de dar salto de qualidade na escavação do conhecimento, por meio das possibilidades de fazê-lo emergir, transcendendo o campo valorativo para a produção epistemológica do conhecimento, pois o conhecimento é como a água que escorre entre os dedos das mãos, o que fica nelas é o molhado, assim é o conhecimento que precisa ser regado como uma planta para florescer, ter vida e frutos.

É preciso então criar condições/possibilidades para erigir o conhecimento em meio à pluralidade de saberes existentes, que devem ser tratados em sua complexidade, 
em seus diferentes níveis de realidade e em sua lógica de terceiro incluído ${ }^{3}$, este último é o que possibilita o nascer do conhecimento cientificamente produzido, pela interpenetração do conhecimento (PINTO, 1970; MORIN, 1999).

\section{O saber/conhecimento no campo da história}

O paradigma cartesiano da produção do conhecimento parece que por séculos imperou e ainda tem se concentrado no campo científico, mediante a razão metódica positivista e empirista. Ao se ampliar o horizonte de sentido acerca do primado do conhecimento, amplia-se também o domínio. Assim a história passa a ser considerada como ciência, daí o seu objeto de estudo por meio da subjetividade tende a ser tratado objetivamente. Desse modo, é destacado que entre o fim do século XVIII e início do XIX, a História ganhou autonomia diante da filosofia e das ciências humanas e, em relação a estas últimas, reivindicou semelhante estatuto de cientificidade (GRESPAN, 2011).

Por conseguinte, tratar da natureza do conhecimento é compreender que a sua produção é histórica, como também é implicada em relações de poder que perpassam por divulgação e circulação nos campos sociais e naturais dos saberes sistematizados em campos diversificados que originam o aparecimento de conhecimentos novos. Assim, segundo Grespan, há preocupação em validar a produção do conhecimento por meio das ciências humanas, inclusive no campo da História, daí há um conflito no processo da produção do conhecimento, tendo em vista que o valor seria dado por meio do experimento, coisa que seria impossível no campo histórico. Este conflito passa a ser desafiador para que a História de fato passe a ter valor no campo da cientificidade como propulsora do conhecimento a partir das narrativas orais, mitos, lendas, fatos - tudo isso são saberes que a história opera com eles, a fim de lhes conferir status de conhecimento no campo científico.

Sendo assim, Grespan defende que "apesar de lidar com o individual, irredutível a leis gerais, ele [historiador] também poderia afirmar a verdade em seu campo de estudo e atingi-la com um grau de certeza razoável" (p. 292). Ou seja, o historiador tem como afirmar a verdade com um grau razoável de certeza, isso porque o conhecimento é absoluto e relativo simultaneamente, daí consagra-se outro saber que não seja o

${ }^{3}$ Compreende-se a lógica do terceiro incluído como tudo o que surge de novo, que agrega, que une, que conecta, que não separa, não dicotomiza e não é dualista, é o conhecimento emergente. 
positivismo lógico e empirista, mas amplia-se na perspectiva da fenomenologia, do materialismo histórico-dialético e do pensamento complexo que norteiam o conhecimento epistemologicamente.

Japiassu (1981) concebe a história das ciências como resultado da complexidade para a produção do conhecimento, embora o seu modo de produção seja disciplinar. Para tanto, entende-se que a produção do conhecimento depende do tipo de método a ser utilizado no campo da sua elaboração, ou seja, a verdade é relativa a depender da forma como se trabalha com o método. Tal como nos explica Grespan, que "o método forneceria a possibilidade de obter a verdade, de saber se nossos pensamentos e nossas proposições sobre determinada matéria são reais, se correspondem a algo existente fora de nossa mente, de modo objetivo" (2011, p. 293), isto significa que o saber é sistematizado por meio do que a realidade apresenta, ou seja, a realidade não é dada, é desvelada através dos instrumentos metodológicos utilizados na produção do conhecimento, levando em consideração a sua complexidade no campo social, embora de forma disciplinar, devido ao uso de determinado método.

\section{O método na produção do saber/conhecimento}

O instrumento da razão possibilita a produção do conhecimento, por viabilizar a correspondência aproximada do sujeito em relação ao objeto investigado. Ação, esta que não é simples, por requerer do sujeito uma postura não neutra, a fim da validação do que foi elaborado e considerado como conhecimento implicado no crivo da objetividade sem negar a subjetividade. Nesta dimensão epistemológica, Grespan (2011, p. 297) afirma que "o método não é neutro, de que o sujeito constrói o conhecimento e de que não há uma objetividade pura tem levado, muitas vezes, até mais longe, revalorizandose a subjetividade em seu sentido mais amplo".

Nesta perspectiva, no campo social da produção do conhecimento fica difícil a descentralização ou separação da objetividade/subjetividade, tendo em vista que o sujeito que produz o conhecimento considera elementos como a identidade, valores, percepções e a aproximação do sujeito em relação ao objeto investigado, como já fora supracitado, tal como é apresentado por Ponty ao abordar a filosofia como domínio da fenomenologia, por considerar o que está no campo da intuição e da imaginação. Pois "a cada instante também eu fantasio acerca de coisas, imagino objetos ou pessoas cuja presença aqui não é incompatível com o contexto, e, todavia, eles não se misturam ao 
mundo, eles estão adiante do mundo, no teatro do imaginário" (PONTY, 2006). É nesta complexidade do campo social que o saber é operado por meio da razão metódica suscitando, portanto, o conhecimento objetivo, refinado, elaborado, sistematizado, ou seja, o refinamento do conhecimento é dado pela forma disciplinar que opera rupturas ao saber e legitima o conhecimento como forma de saber elaborado.

Conforme entendimento de Japiassu, é defendido que existem dois métodos inerentes à produção histórica do conhecimento, os quais estão imbricados aos processos científicos propriamente ditos, no seu campo complexo, bem como por meio da segurança objetiva que permeia a produção do conhecimento inacabado, mas sempre em constante vir a ser. Destarte, salienta-se o movimento dos chamados "acontecimentos científicos" que ocorrem em duas perspectivas: "externalismo e internalismo" (JAPIASSU, 1981), ambas se retroalimentam nas áreas do saber, rompendo fronteiras e alargando os caminhos do saber para a elaboração do conhecimento numa perspectiva disciplinar.

Nesta interconexão, percebe-se que a disciplinaridade é perpassada pela interdisciplinaridade no processo externalístico da produção do conhecimento, pois permeia práticas e técnicas da produção do conhecimento por meio do tratamento dos diversos saberes que corroboram para a produção epistemológica do conhecimento em suas áreas diversas. Em se tratando do processo internalista é pertinente defender que este está mais no campo da objetividade metódica, como a própria ciência se encarrega de circunscrever em sua totalidade. Ou seja, a produção do conhecimento é disciplinar mediante o uso do método cientifico para sua produção, mas o conhecimento em si é interdisciplinar por este ser contido nos acontecimentos científicos que são operados nas diversas áreas de conhecimento.

A interdisciplinaridade é bastante defendida na concepção de Japiassu, pois não há como conceber o conhecimento pelo viés de sua totalidade imersa em pragmatismos totalitários, sem fazer jus às ramificações interconexas que os diversos saberes permeiam ao se elaborar um determinado conhecimento específico sobre algo existente (SANTOS, 2017; MORIN, 1999; BURKE, 2012; PINTO, 1979). Tal como a lupa do pesquisador que amplia os seus achados, assim é a interdisciplinaridade que amplia o horizonte do conhecimento refinado.

Considerar as interfaces e os constructos sociais e históricos na elaboração do conhecimento é perceber que existe uma gama de saberes que correspondem a determinados fenômenos que possibilitam conhecimentos diversos, assim não se pode 
apenas defender uma única área como legitimadora de determinado conhecimento, pois, Grespan (2011, p. 296), afirma que "a interdisciplinaridade se tornou palavra de ordem, uma vantagem reivindicada por cada pesquisa e cada nova área que surge".

Portanto, cada nova área que surge aciona saberes que estão na base para fundamentar o novo conhecimento que emerge de determinada pesquisa, por isso, defende-se que o saber é adisciplinar, ou seja, o saber propriamente dito não está alocado em disciplinas, mas subsidiam as áreas de conhecimento por atravessar outros saberes e permear um novo saber, ou seja, o conhecimento elaborado.

Esta perspectiva do conhecimento disciplinar cientificamente produzido implica na compreensão a partir da relação do sujeito/objeto, que corrobora para o novo emergente nesta relação. Assim, é importante compreender que o domínio/método que opera a produção do conhecimento requer redefinição completa e profunda nas relações que se estabelecem nesta produção. Ação, esta que Grespan (2011) nos orienta no sentido da curiosidade epistemológica para compreender os campos de saberes que viabilizam a transcendência a fim da produção de um determinado conhecimento.

Mediante a produção do conhecimento em seus diversos campos científicos é possível identificar que a sua produção tem uma visão central, unilateral, cartesiana e dogmática, logo, é disciplinar. Desconsiderando assim, as mais variadas possibilidades de saberes que permeiam a organicidade do conhecimento numa perspectiva hipercomplexa, devido à necessidade de erigir o conhecimento elaborado.

Grespan faz uma crítica a esta forma de produção de conhecimento "julgando estéril o saber objetivo, fechado num domínio unilateral, propuseram então considerar predominante à dimensão estética da História - a narrativa como arte, o ponto de vista como estilo" (2011, p. 297). Atenta-se, então para o fato de que quando se pretende enquadrar o conhecimento no campo fechado, num domínio unilateral, inviabiliza-se a ampliação do conhecimento elaborado no campo das ciências sociais e humanas por essas serem holísticas na interpretação, na compreensão, na leitura e na produção de determinado conhecimento que a depender da finalidade é amplo, com várias possibilidades de compreensões, tal como nos é sugerido por Ponty.

Nesta complexidade, é pertinente salientar que o método de produção do conhecimento é que definirá a organicidade, divulgação e circulação deste, pois a pretensão é operar rupturas que historicamente são delineadas nos saberes sistematizados cientificamente, os quais corroboram com o surgimento do conhecimento elaborado, por isso, compreende-se a interconexão que há entre as 
diversas áreas de conhecimento e faz com que emerja outros conhecimentos, assim a disciplinaridade do conhecimento não nega a interdisciplinaridade, pois uma depende da outra e vice-versa, ou seja, são indissociáveis, embora a o conhecimento seja operado disciplinarmente.

Levando em consideração a forma centralizadora da produção do conhecimento, por isso disciplinar, Grespan salienta "a fronteira" existente na sistematização do saber, a fim de que o aparecimento do conhecimento seja inerente às diversas áreas de conhecimento, ou seja, mesmo a produção do conhecimento seja disciplinar, sua circulação transcende a disciplinaridade em que é operado. Desse modo, o conhecimento elaborado é relativo e absoluto simultaneamente, logo a disciplinaridade que o envolve em sua razão metódica deve romper as fronteiras físicas de sua circulação.

\section{O saber/conhecimento e seus desdobramentos complexos}

Reconhecer que no campo das ciências humanas e sociais não há como defender um único saber/conhecimento mediante o uso de determinados métodos da pesquisa social, Bachelard e Bacon contribuíram ao redimensionar o conhecimento na barreira dos obstáculos e ídolos que promovem a flexibilização do método/domínio na elaboração do conhecimento.

O contra-pensamento (Barchelard 1996) é o que permeia o obstáculo na forma como o conhecimento é elaborado a depender dos interesses que se têm ao se elaborar o conhecimento científico, sendo assim, uma barreira rigorosa a ser superada no ato da produção do conhecimento é a limitação presente no campo do obstáculo (aqui entendido como incerteza), pois a disciplinaridade do conhecimento não tem como negar a complexidade desta produção, por meio do tratamento a ser dado aos diferentes saberes hipercomplexos e que destes devem erigir o conhecimento elaborado.

Tal como já foi abordado, a interdisciplinaridade pode promover a ampliação da reflexão sobre o primado do conhecimento através do domínio/método que erige a elaboração do conhecimento, ou seja, não há como defender a elaboração do conhecimento somente pela razão metonímica (razão fechada, absoluta), mas também por outras razões, como: a proléptica (impotente, arrogante e aberta) (SANTOS, 2017). Neste entendimento, a disciplinaridade do conhecimento é limitada no ato de produzir o 
conhecimento, assim, considera-se que a razão metonímica e a proléptica podem ser consideradas como obstáculos para a disciplinaridade do conhecimento.

Mediante esses obstáculos, é concebido, por Barchelard, como obstáculo quando o conhecimento não é permeado pela razão metódica que produz o conhecimento. Assim, define como "logo se perceberia que os conhecimentos objetivos concentram-se muitas vezes em torno de objetos privilegiados, em torno de instrumentos simples que trazem a marca do homo faber" (1996, p. 95). Sendo assim, considera-se que o homo faber é incapaz de produzir o conhecimento, inclusive é alocado no campo empírico de sua organicidade, tal como pode se perceber em conhecimentos empíricos já constituídos: não se trata, portanto, de adquirir uma cultura experimental, mas sim de mudar de cultura experimental, de derrubar os obstáculos já sedimentados pela vida cotidiana (BARCHELARD, 1996). Desta forma, prima-se por um método que possa fazer jus ao experimento para que os saberes possam corroborar com a produção do conhecimento específico e científico a ser concretizado, ou melhor, metodologicamente operacionalizado.

Para tanto, esta produção não pode ocorrer do nada ou do home faber ou ainda do campo empírico, mas sim, deve-se fazer jus à ciência que é capaz de fomentar o conhecimento melhor elaborado, sendo este verdadeiro e autêntico no campo científico de sua existência, tal como salienta Barchelard ao afirmar nesta dimensão a necessidade de primar pela cultura científica legitimadora do conhecimento, por esta mobilizar permanentemente tornando o conhecimento aberto e dinâmico, conferindo a disciplinaridade do conhecimento à sua complexidade, esta entendida como desafio à produção do conhecimento.

Barchelard nos orienta sobre a necessidade de compreender a cultura científica no seu campo aberto, ou seja, romper com todos os paradigmas cartesianos, dogmáticos e centralizadores do campo do conhecimento, em contrapartida os diferentes níveis de realidades permeiam a produção do conhecimento nas mais variadas áreas e entre essas diferentes áreas, retroalimentando assim a dinamicidade que se requer o campo teórico para não ocupar a objetividade metódica, bem redefinida, mas abarcar os diversos campos, maneiras diferenciadas de produzir o conhecimento, por meio do refinamento dos saberes, através de uma razão cosmopolita dentro do domínio da disciplinaridade do conhecimento, pois já deixamos claro que a disciplinaridade não nega a complexidade da produção do conhecimento e a razão cosmopolita tende a se aproximar da totalidade da produção do conhecimento. 
Da mesma forma que o conhecimento não está totalmente preso na natureza, existem outros campos que o permeiam, assim Bacon (1988) assinala que "nenhum saber é absolutamente seguro", isso porque concerne também a "percepções sensíveis" e "dialéticas" que corroboram os diversos saberes que a depender de seus procedimentos metodológicos contribuem para a produção do conhecimento. Ou seja, as ideias de Barchelard e Bacon se aproximam diante do primado do conhecimento, assim como as de Santos no que concerne ao entendimento de cada razão que obstaculariza o primado do conhecimento.

Portanto, "O conhecimento comum é inconsciência de si". Significa que o conhecimento em si é para si quando é elaborado por meio da disciplinaridade do conhecimento. Todavia, a inconsciência pode atingir pensamentos científicos (BACHELARD, 1996). Ou seja, os pensamentos científicos conferem o status da gênese do conhecimento, por si só se sustenta em sua elaboração, à medida em que o seu estado nascente corrobora para que todo e qualquer problema seja esclarecido, por meio da produção disciplinar do conhecimento. Destarte, o método indutivo e experimental que é defendido por Bacon consagra a epistemologia do conhecimento melhor elaborado legitimado pela razão, por ser uma atividade psicológica essencialmente politrópica: procura revirar os problemas, variá-los, ligar uns aos outros, fazê-los proliferar. Para ser racionalizada, a experiência precisa ser inserida num jogo de razões múltiplas. (BACHELARD, 1996). Assim, a forma como apresenta as possibilidades da produção do conhecimento ligando um ao outro, ou seja, o tecido comum, assim se amplia a visão de sua produção, mesmo na sua disciplinaridade, em prol de sua veracidade, da mesma forma que se aproxima da visão de Gadamer, Ruanet, Weber, Marx, Ponty, Pinto, Morin, Santos e Burke, afirmando aqui a disciplinaridade do conhecimento e sua complexidade.

Perceber que a racionalização limita as possibilidades de operacionalização do conhecimento torna-se fundante, pois as relações intersubjetivas interferem na produção do conhecimento nas suas variadas dimensões existenciais e isto deve ser levado em conta. Daí se compreende quando Bachelard nos orienta acerca da "teoria da racionalização discursiva e complexa que tem, contra si, as convicções primeiras, a necessidade de certeza imediata, a necessidade de partir do certo e a doce crença na recíproca, que pretende que o conhecimento do qual se partiu, era certo" (1996, p. 47). Assim, desvela-se que a certeza centraliza as convicções acerca de determinadas convicções como norteadoras da produção do conhecimento. 
O conhecimento objetivo não é de tal modo o suficiente para desvelar o conhecimento verdadeiro ou as razões que podem suscitar acerca do conhecimento, parte do pressuposto da observação, do empirismo ou das convicções que o fundamenta. O que não se poderia validar como conhecimento legítimo, pois seria, aliás, erro grave pensar que o conhecimento empírico pode ficar no plano do conhecimento meramente assertivo, limitando-se à simples afirmação dos fatos (BACHELARD, 1996). Contudo, são necessários aprofundamentos epistemológicos para sistematizar os saberes inerentes a determinado conhecimento elaborado, pois o conhecimento geral é quase, fatalmente, conhecimento vago (BACHELARD, 1996), logo a disciplinaridade do conhecimento confere-lhe a singularidade deste saber elaborado, por ter havido a separação do saber elaborado dos demais saberes do campo geral de sua existência.

Concebendo que a produção do conhecimento não pode se dar pela superficialidade, mas pela profundidade nas coisas que possuem o sentido do mundo e de tudo aquilo que vem a ser, Barchelard chama atenção acerca da forma de Descartes conceituar a produção do conhecimento "dividir cada dificuldade a ser examinada em tantas partes quanto possível e necessário para resolvê-las" (DESCARTES, 1978).

Desta feita, é possível perceber a possibilidade da interdisciplinaridade como fomentadora da produção do saber/conhecimento, pois, mesmo que Descartes parta do método do discurso em busca da verdade, não se nega a necessidade de ampliar o sentido dos saberes por meio da divisão que se encontra em outras matérias para explicar determinados conhecimentos assim elaborados, por isso a psicanálise do conhecimento objetivo deve romper com as considerações pragmáticas do conhecimento, este que está sempre em reconstrução no processo de vir a ser que está nele (BACHELARD, 1996).

O conhecimento à luz de Rouanet (1993) baseia-se nas dimensões do "racionalismo, individualismo e universalismo". Nesta perspectiva, a visão de Rouanet opõe-se à de Kant, pois o primeiro defende a tese de que o ser humano é coercitivo para poder operar mediante a abundância de oportunidades de pensar, ou seja, não há autonomia propriamente dita no campo econômico, político, cultural, histórico, em que os seres humanos se posicionem, pois esses estão submetidos a obediências a quem detém o poder/conhecimento. Daí a complexidade que está implicada no universalismo, bem como os diferentes níveis de realidade inerentes aos campos das diferentes subjetividades a que os seres humanos estão agrupados. A tudo isso Rouanet concebe como uso público e privado da razão. A discussão densa apresentada por Rouanet sobre 
o primado do conhecimento é implicada nas relações de poder que se estabelecem historicamente.

Já a produção do conhecimento na visão de Kant encontra-se inerente na expressão “sapere aude!”, pois é nesta capacidade de ousar, por meio do pensamento livre, usar a razão e construir objetivamente o conhecimento de forma a defender o ponto de vista acerca da premissa maior, a liberdade do pensamento, que é defendida por Descartes ao mencionar que a condição de criança submete-o à autoridade da dependência dos outros, logo, é preciso superar as barreiras sociais e culturais que limitam a produção do conhecimento. Desta forma, Descartes e Kant se aproximam em defender o primado do conhecimento por meio da complexidade que está ancorada no positivismo/empirista.

Assim, "são, pois, muito poucos apenas os que conseguiram mediante a transformação do seu espírito arrancar-se à menoridade e encetar então um andamento seguro" (KANT, 2017), ação esta necessária para que por meio do uso da razão possa se construir e reconstruir, quantas vezes necessárias for, o conhecimento em campos específicos de sua complexidade. Tal como nos alerta Kant, ao afirmar que temos apenas claros indícios de que se lhes abre agora o campo em que podem atuar livremente e diminuem pouco a pouco os obstáculos à ilustração geral ou à saída dos homens da menoridade de que são culpados (KANT, 2017), tal como Ruanet (1993) que aborda a obediência mediante as dimensões territoriais da constituição do conhecimento, por meio da obediência.

\section{A complexidade do conhecimento em sua complexidade}

Compreender o método filosófico em prol da produção do conhecimento é conceber a complexidade que perpassa os sentidos humanos, como tato, paladar, audição, visão e olfato no ato que subsidia a multirreferencialidade que se faz pertinente para produção do conhecimento. De tal modo, Ponty (2006) nos alerta no sentido de que "o mundo não é aquilo que eu penso, mas aquilo que eu vivo; eu estou aberto ao mundo, comunico-me indubitavelmente com ele, mas não o possuo, ele é inesgotável" (p. 14). Assim é inesgotável a possibilidade de produção do conhecimento, mesmo sendo ele disciplinar. Deste modo, ao que concerne ao 'inesgotável do mundo', da mesma forma é o conhecimento que se retroalimenta conforme cada saber, domínio, sujeito, objeto, linguagem e realidade. Pois bem, é mediante essas categorias que o conhecimento se 
constrói numa complexidade a depender da razão metódica de quem o produz, como o produz e, sobretudo, de como é erigido e acionado que permeia o vir a ser da disciplinaridade do conhecimento e sua complexidade, isto já explicado.

Numa dimensão sociológica é importante salientar o que Weber expõe no campo sociológico acerca do primado do conhecimento, pois a sociologia compreensiva, entretanto, não se interessa pelos fenômenos fisiológicos e pelos anteriormente chamados fenômenos 'psicofísicos' [...], tampouco se interessa pelos dados físicos brutos... Pelo contrário, estabelece diferenças da ação conforme referências típicas providas de sentido [...]" (WEBER, 1995, p. 315). Compreendam que o sentido é o que delimita a compreensão de fenômenos externos e internos que se coadunam ao devir do conhecimento e que é de sobremaneira importante para sua sistematização. O sentido fenomenal que se estabelece na visão weberiana possibilita a interpenetração dos saberes que corroboram para a elaboração do conhecimento, desconstruindo, portanto, o positivismo/empirista que prima por um método das ciências da natureza para definir variáveis do conhecimento. Numa contravisão das ciências da natureza, Weber (1995) se coloca no campo da sociologia dos sentidos, ou seja, nas ciências sociais, como possibilidade da produção do conhecimento.

A complexidade que permeia o devir do conhecimento também está no campo filosófico à luz de Ponty (2006), ao afirmar que "o conhecimento aparece como um sistema de substituições em que uma impressão anuncia outras sem nunca dar razão delas, em que palavras levam a esperar sensações, assim como a tarde leva a esperar a noite" (p. 38). Compreende-se assim, que o conhecimento sendo um sistema de substituições por meio do uso da percepção que leva a operar as sensações de sua produção é impregnado de sentidos e significados a depender da interpretação do sujeito com o seu objeto, bem como o usa da linguagem sobre a realidade, assim como a utilização do método/domínio a favor da sensação que é intrínseca da subjetividade operando na objetividade, sendo assim, complexo o processo da disciplinaridade do conhecimento.

A produção do conhecimento está arraigada com o campo da percepção e da sensação que filosoficamente perpassa para além do domínio. Tal como nos chama atenção Ponty, ao mensurar que "o conhecimento nunca tem domínio sobre seus objetos, que se ocasionam um ao outro, e o espírito funciona como uma máquina de calcular que não sabe por que seus resultados são verdadeiros" (2006, p. 38). O fato de não ter domínio sobre o objeto significa dizer que os objetos são perceptíveis 
diferentemente de seus sujeitos ao olharem para ele, assim sendo, a subjetividade ganha dimensão significativa para operar a elaboração do conhecimento, sendo este singular em meio à pluralidade de visões que se estabelecem sobre o mesmo objeto, mas que por meio do método e ou domínio se diferencia mediante a individualidade do sujeito ao relacionar-se com seu objeto.

Nesta mesma perspectiva defende Pinto, pois "o todo do conhecimento presente em cada época se constituiu pela acumulação destes atos singulares, que são as distintas pesquisas das realidades empreendidas cada qual num determinado instante, num determinado lugar, por um investigador individual" (1979, p. 14). Refletindo sobre a concatenação do conhecimento por meio da pesquisa em sua produção, salienta Ponty acerca da singularidade de cada investigador, ciente desta premissa concebe-se que "essa conversão do olhar, que inverte as relações entre o claro e o obscuro deve ser efetuada por cada um e é em seguida que ela se justifica pela abundância dos fenômenos que permite compreender" (2006, p. 49). Logo. Ponty e Pinto têm visão singular à pluralidade do conhecimento enquanto categoria geral.

O tratado do primado do conhecimento à luz de Gadamer em prol do fenômeno/objeto no campo da hermenêutica fenomenológica dá ênfase a linguagem/realidade, bem como à compreensão interpretativa dos fenômenos. Assim, comunga-se do pressuposto a priori da desconstrução do campo positivista/empirista que se perdurou por séculos como mentor e mantenedor da produção do conhecimento disciplinar. Neste sentido, a conhecida polêmica entre Hegel contra "a coisa em si" kantiana pode tornar isto mais claro. A delimitação crítica da razão, por Kant, tinha restringido a aplicação das categorias aos objetos da experiência possível, declarando incognoscível, por princípio, a coisa em si, que subjaz aos fenômenos (GADEMER, 2012, p. 507).

O conhecimento em sua gênese tem originalidade, logo não se precisa negar o que já foi construído e seu modus operandi. Neste sentido, Santos (2017) explica com seu primado sobre a sociologia das ausências, sendo interessante compreender que nenhum teórico dará conta da totalidade existencial em que o conhecimento se faz. Daí a necessidade, razão cosmopolita que rompe com os obstáculos da produção do conhecimento.

O primado do conhecimento, sob a ótica de Pinto (1979, p. 14), significa que "o todo [fenômeno] se constitui a partir dos elementos, estes só se explicam e se tornam possíveis pela precedência da totalidade que dá origem a cada novo ato de pesquisa." É 
nítida a complexidade como propulsora do conhecimento, este que se diferencia dos saberes que o envolve, por meio da singularidade que lhe tem sido peculiar.

Dando ênfase a esta peculiaridade, no campo da pesquisa social, ao considerar os fatos sociais (DURKHEIM, 1999) existe uma abundância de fenômenos sociais que devem ser investigados/observados em sua singularidade sem negar a totalidade que os envolvem, sendo assim, escavada pelos procedimentos metodológicos como reconstrutor do novo que emerge do que outrora fora construído.

A disciplinaridade do conhecimento e sua complexidade estão emaranhadas nos domínios metodológicos que a fazem, pois, considerando o que Ponty, afirma sobre a importância do saber como percussor do conhecimento elaborado, quando diz "para tomar posse do saber atento, basta-lhe voltar a si, no sentido em que se diz que um homem desmaiado volte a si”. (2006, p. 54). Esta premissa promove o ato da reflexão, pois ao refletir sobre os saberes que ainda não são conhecimentos, heuristicamente a reflexão no campo da pesquisa possibilita o tratado do saber atento como conhecimento a ser construído em meio ao saber sem rigor metódico. Da mesma forma, Pinto defende que "o pensamento apreende de si mesmo ao produzir os seus elementos constituintes, as ideias que refletem a realidade dos objetos ou fenômenos a cujo exame se aplicou" (1979, p. 16).

Todavia, paulatinamente, o conhecimento a ser produzido é mediado pela reflexão criteriosa acerca do objeto atentamente depreendido epistemologicamente em sua produção a escavar a realidade perpassada por diversos fatos sociais (objetos ou fenômenos) que dedutivamente é trabalhado pelo criterioso exame aplicado em sua produção a partir da sistematização do saber.

Nesta lógica, corrobora Pinto ao afirmar que o conhecimento é constituído simultaneamente por sua reflexão, pois "ao mesmo tempo em que aciona a atenção, a cada instante o objeto é reapreendido e novamente posto sob sua dependência" (1979, p. 59). Sendo assim, salienta-se que o conhecimento objetivo pode ser investigado, analisado e reconstruído por sua flexibilidade existencial, isto é, o que é agora, já não foi ontem e nem assim será amanhã, simplesmente o conhecimento é fluido, ou seja, todo conhecimento é transitório, não existe conhecimento fixo, existe conhecimento universal, mas não absoluto, único e imutável, pois está sempre sendo reapreendido.

Deste modo, é interessante o que é defendido por Popper acerca da falseabilidade como estratégia metodológica da produção do conhecimento, pois "ao buscar o conhecimento puro, nosso alvo é, muito simplesmente, compreender as 
perguntas como e perguntas de por quê?” (1975, p. 240). Significa que existem estratégias específicas para desmembrar o conhecimento, tal como consta nesta assertiva "sede tão claros quando puderdes a respeito de vosso problema e vigiai o modo por que ele se altera e se torna mais definido" (1975, p. 243). Já, no que concerne à visão de Durkheim, concebe-se que "é preciso, portanto, considerar os fenômenos sociais em si mesmos, separados dos sujeitos conscientes que os concebem" (1999, p. 28). Destarte, é importante imprimir a compreensão que, diante da singularidade existencial de cada ser, determinados fenômenos são percebidos diferentemente pelas consciências plurais ao se debruçar sobre o mesmo fenômeno investigativo.

Tratar do conhecimento é antes de tudo concebê-lo como um vir a ser, em meio ao que já é existente de diferentes formas e conteúdos. Nesta hipercomplexidade (MORIN, 1999) que o envolve, basta ao seu criador inovar, fazer emergir a coisa que emana daquilo que ainda não fora perceptível por outrem, mas que, ao escavar com determinado domínio, pode-se fazer romper, tal como as águas que minam das profundezas da terra.

Logo se pode erigir que o conhecimento é dinâmico e dialético, pois por meio da consciência individual, a qual nesta individualidade se faz presente a pluralidade do ser humano pela sua inserção social múltipla, com fatos sociais múltiplos e interações sociais (BURKE, 2012 e SANTOS, 2017), assim se estabelece o primado do conhecimento operado também pelo método histórico-dialético, do qual emergem outras demandas do "particular ao geral" (MARX, 1977). Neste sentido, há uma contribuição importante de Marx em prol do conhecimento erigido no campo histórico, que perpassa o campo econômico, político, cultural, filosófico e também sociológico. Daí não tem como não aproximar as ideias de Marx com as de Ruanet, ambas os autores teorizam sobre a universalização do conhecimento em que, a depender da situação, "obedeça".

Contestar a feitura do conhecimento pelo crivo da razão em seus diversos campos/áreas é buscar entender a universalidade do conhecimento pela necessidade emergente de operar em determinadas categorias mais amplas que retroalimentam numa dimensão interpenetrante entre os pores teológicos e a causalidade do conhecimento (LUKÁCS, 2010).

Weber, Marx, Lukács e Ruanet são teóricos que têm razões aproximadas acerca da totalidade do conhecimento, pois estes acionam determinadas categorias, sendo as mesmas, mas analisadas por suas respectivas visões singulares que diante da singularidade de cada um torna o conhecimento plural, total e transversal, corroborando 
para que esteja no campo da sua complexidade, uma vez que as categorias, como trabalho, ideologia, social, economia, política e outras são tratadas por eles em suas consciências individuais.

Nessa interpenetração Morin (1999) acrescenta informações importantíssimas para a produção do conhecimento, pois inclusive disserta com precisão sobre o conhecimento. Uma vez que "o conhecimento pode relativamente emancipar-se numa vida humana, mas não conseguiria liberta-se da vida" (1999, p. 249), ou seja, é a atividade humana que o produz, logo ele não existe por si, pois somente o humano é capaz de o produzir por meio das relações que são estabelecidas histórica, social, física e ambientalmente. Nesta perspectiva, faz-se jus a assertiva de Morin quando menciona que "nem na terra, nem nos céus, nem acima destes existe conhecimento absoluto" (1999, p. 253), logo pode ser fluído, flexível em seu existir, permeável como solo regado que faz a semente germinar da terra.

Por conseguinte, é nesta liquidez de conhecimento que se comunga da premissa de que:

O conhecimento do conhecimento requer um pensamento complexo, o qual perpassa pelo diálogo trinitário entre o conhecimento reflexivo (dimensão filosófica), o conhecimento empírico (dimensão científica) e o conhecimento do valor do conhecimento (dimensão epistemológica) para construir o circuito, sempre realimentado com reflexões e conhecimentos, do conhecimento do conhecimento (MORIN, 1999, p. 283).

Assentar a necessidade de compreender sobre a dimensão do conhecimento do conhecimento, sendo esta uma emergência que os autores Morin, Burke e Santos adentram acerca da hipercomplexidade que emerge na especificidade da produção do conhecimento, remete-nos à necessidade de aprofundamentos epistêmicos. Há negação, ocultação, silenciamento e anulação de determinados conhecimentos que cientificamente ainda não se emanciparam (Burke, 2012). Também para Santos "Os outros saberes, não científicos nem filosóficos, e, sobretudo, os saberes não ocidentais, continuaram até hoje em grande medida fora do debate" (2017, p. 241). Vale salientar que é preciso combater a dicotomia acerca do conhecimento [a negação da negação do conhecimento], sendo esta uma recomendação de Santos e Burke, pois ambos mencionam a necessidade de operar rupturas neste constructo histórico, na intenção de que, para haver mudanças profundas na estruturação do conhecimento, é necessário começar por mudar a razão que preside tanto aos conhecimentos como à estruturação 
deles (SANTOS, 2017). Assim, em detrimento da monocultura do saber e do rigor do saber (2017, p. 247) surge a ecologia de saberes (2017 p. 250) que tende a integrar, unir, fazer emergir aquilo que ainda está oculto no campo do conhecimento. Deste modo, não se pode tratar o conhecimento tão somente com uma razão/visão, pois este é pluri, hipercomplexo e interpenetrado em suas diversas áreas, não é somente disciplinar, constituído isoladamente, mas é também interdisciplinar, estando integrado, associado e ramificado como um bambu.

Neste sentido, o primado do conhecimento atravessa a razão epistêmica numa hipercomplexidade que perpassa todas as áreas de conhecimento, por meio do entendimento de que o conhecimento é disciplinar, isso porque, a razão metódica é disciplinar.

\section{O que considerar?}

A reflexão teórica a qual me propus, sobre a natureza epistêmica do saber/conhecimento, definindo-o na dimensão da complexidade (incerteza e desafio) por meio dos seus sentidos e significados, levou-me a entender que não existe isolamento racional no primado do conhecimento, pois este é constituído simplesmente por sua evolução epistêmica perpassada por operações físicas, biológicas, históricas e sociais arraigadas no modus operandi do conhecimento a ser refinado paulatinamente.

A disciplinaridade do conhecimento perpassa pelo entrosamento das ideias que podem ser acionadas em áreas disciplinares múltiplas, ou seja, uma ideia (objeto) pode ser subjetivamente tratada pela objetividade de outras áreas disciplinares, como exemplo, deixo aqui registrada a categoria tempo, pois este pode ser tratado em história, geografia, física, química, matemática, português e outras. A complexidade crescente pode definir a disciplinaridade do conhecimento como líquido, fluido e flexível, pois colocar o conhecimento no campo social, este qualitativamente ganha multirreferencialidade imbricado no campo complexo do conhecimento a vir a ser, sendo e renascendo em seu nascer diante da disciplinaridade do modus operandi que lhe confere status de conhecimento.

Da história do conhecimento depreende-se que a sua produção dar-se-á sempre pela evolução da reflexão sobre as possibilidades existentes, assim é o que acontece no primado do conhecimento singularmente construído, pelas plurais visões que o 
enquadraram em determinados métodos/domínios, sendo que se reconstrói a partir do já construído/existente.

Desse modo, salienta-se que, desde autores clássicos (positivistas/empiristas) aos autores contemporâneos, muda-se apenas a forma, o método e procedimentos metodológicos, isto é, o como falar cientificamente acerca de determinados objetos (saber/conhecimento) que sendo esses trabalhados metodologicamente permeiam a insurgência do novo, mas, afinal, o que é o novo no campo epistêmico do conhecimento se a produção do conhecimento parte do que já existe?

O diálogo aqui estabelecido não teve a pretensão de centralizar em profundidade o aporte epistemológico que subsidiou a respectiva reflexão, pois perceber que o conhecimento é um campo aberto de possibilidades de operações múltiplas que permeiam a ampliação da disciplinaridade do conhecimento em sua complexidade é, antes de tudo, compreender que como não se tem a certeza de sua gênese, tal qual não terá a certeza de sua conclusão, do seu fim em si mesmo, daí a disciplinaridade do conhecimento, nos diversos campos de sua produção, cientificamente elaborado.

\section{REFERÊNCIAS}

BACHELARD, Gaston. A formação do espírito científico: contribuição para uma psicanálise do conhecimento. Trad. Estela dos Santos Abreu. Rio de Janeiro: Contraponto, 1996.

BACON, Francis. Novum Organum: ou verdadeiras indicações acerca da interpretação da natureza; Nova Atlântida. Trad. José Aluysio Reis de Andrade. 4 ed. São Paulo: Nova Cultura, 1988.

BURKE, Peter. Uma história social em três dimensões. In: Uma história social do conhecimento II: da enciclopédia à Wikipédia. Trad. Denise Bottmann. Rio de Janeiro: Zahar, 2012.

DESCARTES, René. Discurso sobe o método. Trad. Márcio Pugliesi e Norberto de Paula Lima. São Paulo: Hemus, 1978.

DURKHEIM, Emile. As regras do método sociológico. Trad. Eduardo Brandão. 2. ed. São Paulo: Martins Fontes. 1999.

GADAMER, Hans-Georg. Verdade e método I: traços fundamentais de uma hermenêutica filosófica. Trad. de Flávio Paulo Meuer. 12 ed. Petrópolis, RJ: Vozes; Bragança Paulista: Editora Universitária São Francisco, 2012.

GRESPAN, Jorge. Considerações sobre o método. In: PINSKY, Carla Bassanezi et al. (Org.). Fontes históricas. São Paulo: Contexto, 2011. 
JAPIASSU, Hilton. O problema da história das ciências. In: Questões epistemológicas. Rio de Janeiro: Imago, 1981.

KANT, Immanuel. O que é o iluminismo. Disponível em:

<http://www.lusosofia.net/textos/kant_o_iluminismo_1784.pdf >. Acesso em: $07 \mathrm{de}$ mar. 2017.

LUKÁCS, György. Prolegômenos para uma ontologia do ser social: questões de princípios para uma ontologia hoje tornada possível. Trad. Lya Luft e Rodnei Nascimento. São Paulo: Boitempo, 2010.

MARX, Karl. Contribuições à crítica da economia política. São Paulo: Martins Fontes, 1977. Prefácio, p. 23-27; O método da economia política, 218-227.

MORIN, Edgar. Conclusões: possibilidades e limites do conhecimento humano. In: O método 3: o conhecimento do conhecimento. Trad. Juremir Machado da silva. Porto Alegre: Editora Sulina, 1999.

PINTO, Álvaro Vieira. A evolução do conhecimento. Os caracteres do conhecimento científico. In: Ciência e existência: problemas filosóficos da pesquisa científica. 2. Ed. Rio de Janeiro: Paz e Terra, 1979.

PONTY, Maurice Merleau. Fenomenologia da percepção. Trad. Carlos Alberto Ribeiro de Moura. São Paulo: Martins Fontes, 2006.

POPPER, Karl R. A evolução e a árvore do conhecimento. In: Conhecimento objetivo: uma abordagem evolucionária. Trad. Milton Amado. Belo Horizonte: Editora Itatiaia; São Paulo: Editora da Universidade de São Paulo, 1975.

ROUANET, Sérgio Paulo. In: Mal-estar na modernidade: ensaios. São Paulo: Companhia da Letras, 1993.

SANTOS, Boaventura de Sousa. «Para uma sociologia das ausências e uma sociologia das emergências», Revista Crítica de Ciências Sociais [Online], 63 | 2002.

WEBER, Max. Sobre algumas categorias da Sociologia compreensiva. In:

Metodologias das ciências sociais. Parte II. 4 ed. São Paulo: Cortez; Campinas, SP: Editora Estadual de Campinas, 2001. p. 313-348.

\section{Como citar este artigo:}

VIEIRA DE MELO, Maria Aparecida; JOÃO CARLOS, Erenildo. O saber/conhecimento: campos epistêmicos. Temas em Educação e Saúde, Araraquara, v.14, n.1, p. 62-81, jan./jun., 2018. E-ISSN: 2526-3471. DOI: 10.26673/rtes.v14.n1.2018.10803. 